\title{
Protective Effect of Chrysin on Corneal Structural Alterations Induced by Sofosbuvir in Male Albino Rats (Histological and Immunohistochemical Study)
}

Noura H. Mekawy ${ }^{*}$, Heba M. Abdel-aziz and Nahla E. Ibrahem

*Correspondence: dr_nora184@yahoo.com

CrossMark

$\leftarrow$ Click for updates

Department of Histology and Cell Biology, Faculty of Medicine, Zagazig University, Egypt.

\begin{abstract}
Background: Sofosbuvir is a nucleotide analog that has activity against all hepatitis c virus genotypes. Aim of work: The aim of this study was to demonstrate the effect of Sofosbuvir on the cornea of adult male albino rat.

Materials and methods: Thirty five adult male albino rats were used in this experiment. Animals were divided into three groups; Group I control (negative and positive), Group II received Sofosbuvir orally by gastric tube at a dose of $4 \mathrm{mg} / \mathrm{kg}$ per day for 5 weeks. Group III (Sovaldi and Chrysin treated), received SOV as in group II and Chrysin was given orally by a gastric tube, at a dose of $50 \mathrm{mg} / \mathrm{kg}$ once daily for 60 days. All rats were examined for histological study using Hematoxylin and Eosin and Mallory trichrome stains. Immunohistochemical expression for E-cadherin and Caspases-3 was performed. Morphometric and statistical analysis were also performed.
\end{abstract}

Results: Examination of H\&E stained sections of Sovaldi- treated cornea showed irregular upper free surface together with desquamation of surface epithelial cells. Bowman's layer was interrupted and separated. Stroma showed irregularly arranged collagen fibers and separated by wide spaces. Mallory trichrome stained- sections revealed disorganized collagen fibers. Immunohistochemically there was decrease of E-Cadherin expression and dramatically up-regulated expression of Caspases.

Conclusion: Sofosbuvir have detrimental histological and immunohistochemical changes in cornea and Chrysin attenuate these changes.

Keywords: Sofosbuvir, Chrysin, Cornea, E-cadherin, Caspases

\section{Introduction}

Sofosbuvir is commercially known as Sovaldi (SOV), it is a nucleotide analogue polymerase inhibitor used in combination with other drugs to treat hepatitis $\mathrm{C}$ virus (HCV) infection. It has been marketed since 2013. On comparing SOV- based regimens to previous treatments, it provides a higher cure rate, fewer side effects, a two- to four-folds reduced duration of therapy and great difficulty for resistance development $[1,2]$. SOV is a prodrug using the proTide biotechnology strategy. It is converted to the active antiviral agent 2 '-deoxy-2'-a-fluoro$\beta$-C- methyluridine- $5^{\prime}$-triphosphate. The triphosphate acts as a defective substrate for the NS5B protein, which is the viral RNA polymerase, thus acts as an inhibitor of viral RNA synthesis
[3]. It was reported that SOV treatment displays common side effects including fatigue, headache, nausea, rash and irritability [4], other adverse side effects were recorded as chest pain, memory impairment, dyspnea, gastrointestinal reflux, alopecia, depression, muscle spasm and blurred vision. However, the most commonly reported side effects are brain fog (confusion, memoryloss and sudden blankness) [5]. Moreover, vision loss seems to be a growing side effect of Sovaldi [6].

Flavonoids are natural phenolic compounds present in fruit and vegetable species [7]. Flavonoids have many useful effects that include being antioxidants and having anti-bacterial, anticancer, anti-mutagenic and anti-inflammatory properties [8]. Chrysin (5, 7-dihydroxyflavone; is a natural flavonoid available 
in many plant extracts including the blue passion (Passiflora caerulea) flower, bee propolis and honey [9]. Chrysin (CR) has free radical elimination effects with the hydroxyl groups of CR [10]. Like the flavonoids, CR has several pharmacological effects such as being an antioxidant, anti-inflammatory, antiaging, anti-cancer and anti-hypertensive properties [11]. The aim of this study was to investigate the possible protective effects of $C R$ against Sovaldi induced corneal changes in rats.

\section{Methodology}

Drugs and chemicals

1- Sofosbuvir, a product of Pharco Pharmaceuticals, Alexandria, Egypt, was available in the form of tablets with the trade name Gratisovir Each tablet contained $400 \mathrm{mg}$ of Sofosbuvir.

2-Chrysin is currently available as dietary supplement products contain $500 \mathrm{mg}$ of chrysin per capsule, and was purchased from Sigma-Aldrich Chemical Company, (St. Louis, MO, USA).

\section{Animals}

Thirty five adult male albino rats were used in this experiment; each of them is weighing 150-200 grams. Food and water were provided ad libitum for 7 days before use in the animal house, faculty of medicine, Zagazig University. All aspects of animal care and treatment were carried out according to the local guidelines of the ethical committee for animal research.

\section{Experimental design}

The animals were divided into three groups:

Group I (Control): Included fifteen rats, it was subdivided into 2 subgroups:

Subgroup I (negative control group): Included five rats, they were received no treatment throughout the period of experiment.

Subgroup II(positive control group): Included ten rats, they were subdivided into 2 equal subgroups:

Subgroup Ila: The rats received distilled water orally for 5 weeks.

Subgroup Ilb: Rats received Chrysin dissolved in in $10 \mathrm{ml}$ distilled water at a dose of $50 \mathrm{mg} / \mathrm{kg}$ once daily for 60 days.

Group II (SOV-treated): Included ten rats that received SOV, Each tablet contained $400 \mathrm{mg}$ of Sofosbuvir; these tablets were dissolved in distilled water and given for rats orally by gastric tube in a dose of $4 \mathrm{mg} / \mathrm{kg}$ per day for 5 weeks.

Group III (SOV and CR treated): Included ten rats that received SOV as in groupll and CR was given orally by a gastric tube, at a dose of $50 \mathrm{mg} / \mathrm{kg}$ once daily for 60 days [12].

\section{Methods \\ Histological study}

The specimens were fixed in $10 \%$ neutral-buffered formalin, dehydrated in a graded ethanol series, cleared in xylene, and embedded in paraffin wax. Tissue sections of 5-7 $\mu \mathrm{m}$ thickness were cut using a rotating microtome, deparaffinized with xylene, and stained with H\&E and Mallory trichrome for light microscopic examination of the cornea [13].

\section{Immunohistochemical study}

Immunohistochemical reactions were carried out using the avidin-biotin peroxidase complex (Dako Company, Wiesentheid/Bavaria, Germany, Biotin Blocking System, Code X0590) method following the manufacturer's instructions. $4 \mu \mathrm{m}$ serial sections of paraffin-embedded specimens were deparaffinized on charged slides. The sections were incubated in $0.1 \%$ hydrogen peroxide for $10 \mathrm{~min}$ to block the endogenous peroxidase activity and then incubated with the primary antibody.

1. Primary mouse monoclonal antirat E-cadherin antibody, (NeoMarkers/Lab Vision, Fremont, California, USA).

2. Primary mouse monoclonal antirat Caspases 3 antibody (Labvision Corporation; Thermoscientific, USA). The slides were incubated with the secondary antirabbit antibody versal kits (Zymed laboratories), diluted 1:200 for $30 \mathrm{~min}$, and staining was completed by incubation with chromogen, called diamiobenzidine (DAB). Mayer's hematoxylin was used as a counterstain [14].

\section{Morphometric study}

A detailed morphometric analysis of area percentage of collagen in Mallory trichrome stained section, area \% of E-cadherin and optical density of Caspases-3 in immunohistochemical stained sections. Data were obtained using Leica Qwin 500 image analyzer computer system in the image analysis unit in Pathology Department, Faculty of Dentistry, Cairo University. The image analyzer consisted of a colored video camera, a colored monitor and a hard disc of IBM personal computer connected to the microscope, and controlled by Leica Qwin 500 software. The image analyzer was first calibrated automatically to convert the measurement units (pixels) produced by the image analyzer program into actual micrometer units.

\section{Statistical analysis}

Data for all groups were expressed as mean $\pm S D X \pm S D$ ). The data obtained from the image analyzer and the biochemical data were subjected to SPSS program version 14 (Chicago, Illinois, USA). Statistical analysis using the one-way analysis of variance test was carried out. The results were considered statistically significant as $\mathrm{P}$ value was less than 0.05 .

\section{Histological results}

Histological examinations of control subgroups showed similar morphologic results. So, subgroup la was considered as the control group.

H\&E- stained corneal sections of the control group showed the normal structure of five layers (epithelium, Bowman's layer, stroma, Descemet's membrane and endothelium). The epithelium of the cornea was stratified squamous epithelium with smooth and regular free surface. There was a non-cellular homogenous acidophilic layer; Bowman's layer beneath the 
epithelium. Stroma was formed of regularly arranged bundles of collagen fibers that were parallel to each other and to the surface. Keratocytes (corneal fibroblasts) were seen between the collagen fibers. They were flat cells with elongated spindle shape nuclei. Under the stroma there was the Descemet's membrane which appeared as a thin homogenous acidophilic layer. Lastly, a single layer of flat cells with flat or oval nuclei (corneal endothelium) was present on the posterior surface of Descemet's membrane (Figure 1).

Group II (SOV treated) revealed variable changes in the cornea. The less apparently affected areas showed mild interruption of Bowman's layer and separation from the epithelial layer. Minimal separation of corneal stromal fibers was also noticed. The more affected areas revealed disturbance of the normal corneal architecture in the form of irregular upper free surface together with desquamation of surface epithelial layers. Some sections showed thinning of the epithelium. Corneal stroma collagen fibers were irregularly arranged and separated by wide spaces. Keratocytes were decreased in number and degenerated in most of animals with shrunken nuclei (Figures 2a-2c).

Group III (SOV and CR-treated) showed less degenerative changes in cornea; more or less normal appearance of corneal epithelium, Bowman's membrane, stroma and Descemet's membrane (Figure 3).

Mallory trichrome- stained section of the cornea of control albino rat showed regularly arranged bundles of collagen fibers (Figure 4a). While, SOV-treated group revealed many spaces between collagen fibers with disorganized arrangement (Figure 4b). On the other hand, SOV and CR-treated groups howed some spaces between collagen fibers with more or less regularly arranged (Figure 4c).

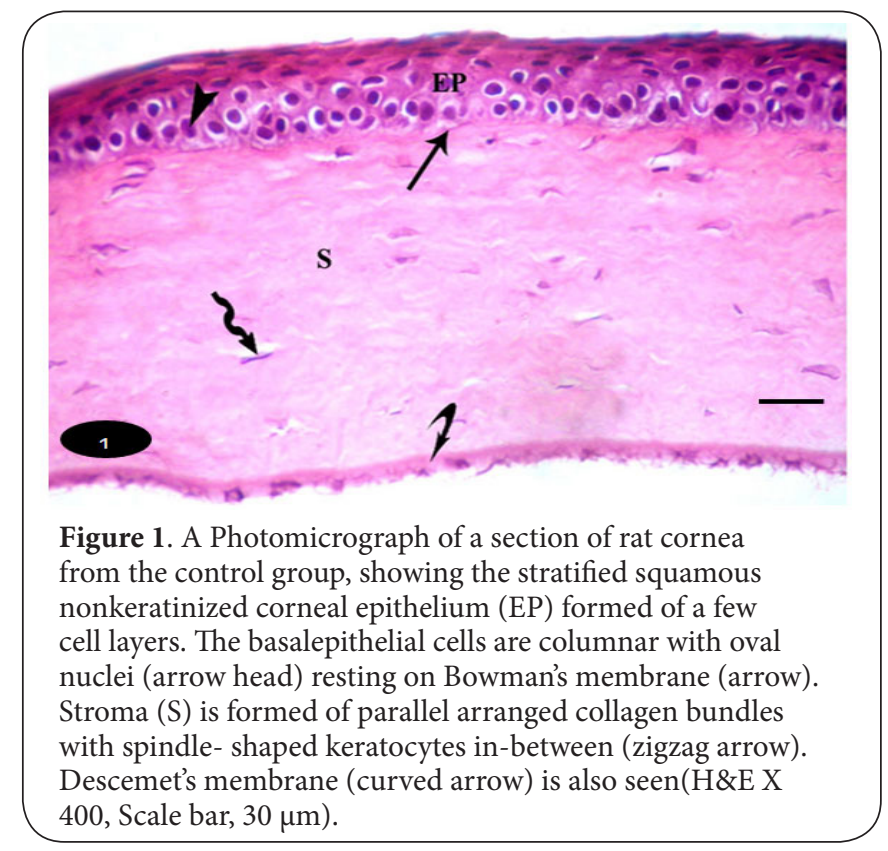

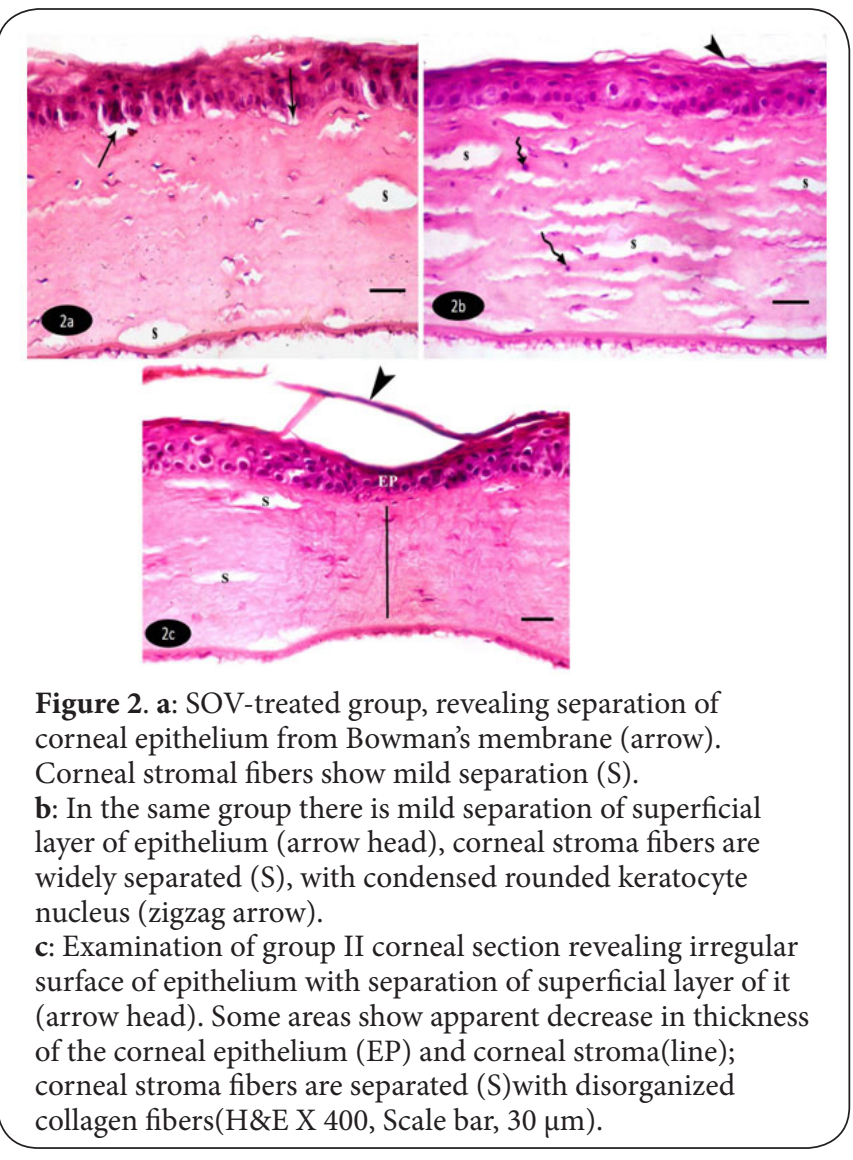

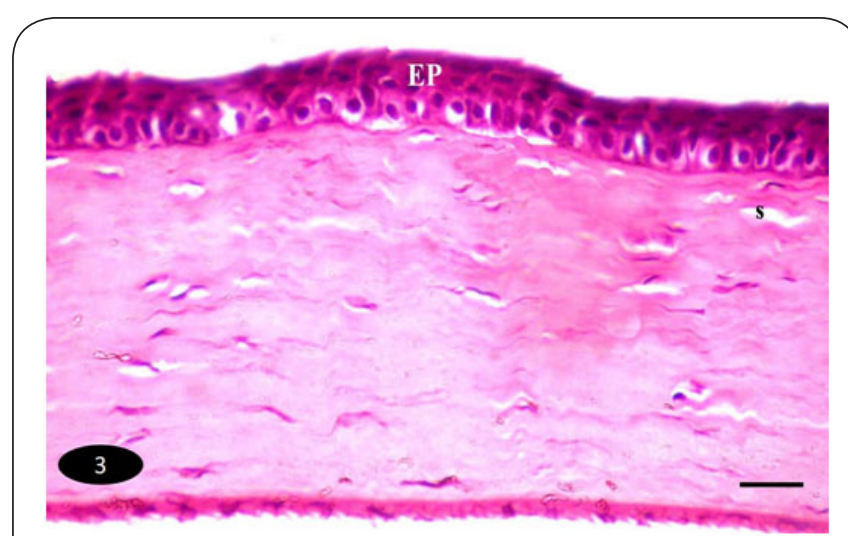

Figure 3. SOV and CR-treated group showing normal thickness of corneal epithelium (EP), slight separation of corneal stroma (S)with apparently regularly arranged collagen fibers(H\&E X 400, Scale bar, $30 \mu \mathrm{m})$.

\section{Immunohistochemical results}

Examination of corneal stained sections of the control group revealed excessive expression of E-cadherin immunoreactions (Figure 5a). While, SOV- treated group showed down-regulation of E-cadherin immunoexpression (Figure 5b) Sovaldi and CR-treated group revealed moderate immunoexpression of E-cadherin (Figure 5c). 


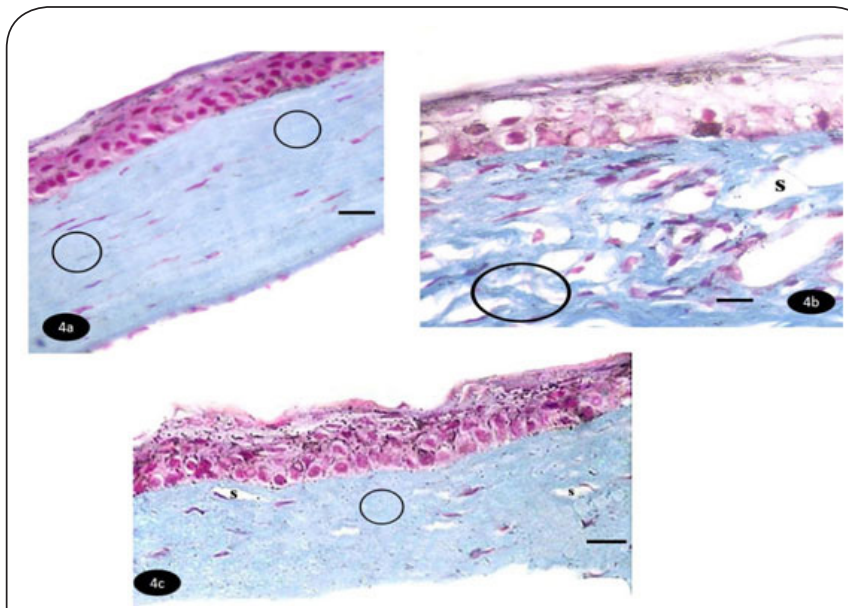

Figure 4. a): A Photomicrograph of Mallory trichrome-stained section of cornea of control albino rat showing regularly arranged bundles of collagen fibers(circle) with no spaces. b): Sovaldi-treated group revealing irregularly distributed collagen fibers (circle) with many spaces (S) in-between.

c): Sovaldi and CR-treated group showing regularly distributed collagen fibers (circle) with some spaces(S) in-between (Mallory trichrome X 400, Scale bar, $30 \mu \mathrm{m}$ ).

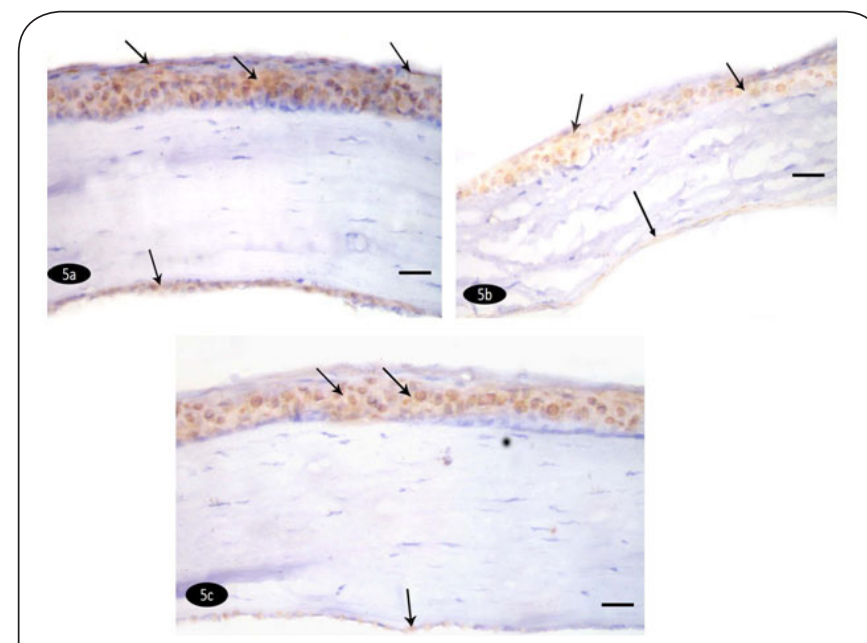

Figure 5. a): A Photomicrograph of immunohistochemicalstained corneal sections for E-cadherin of the control group revealing upregulation of $\mathrm{E}$-cadherin immunoexpression (arrow)

b): Sovaldi-treated group showing down regulation of E-cadherin immunoexpression(arrow)

c): Sovaldi and CR-treated group revealing moderate immunoexpression of E-cadherin (arrow) (Immunoperoxidase for E-cadherin X400, Scale bar, $30 \mu \mathrm{m})$.

Immunohistochemically- stained corneal sections of the control group revealed weak caspases-3 immunoexpression (Figure 6a) While, SOV-treated group showed dramatically up-regulated immunoexpression of caspases3positive cells (Figure 6b): On the other hand Sovaldi and CR-treated group showed moderate immunoexpression positive cells (Figure $6 \mathrm{c}$ ).

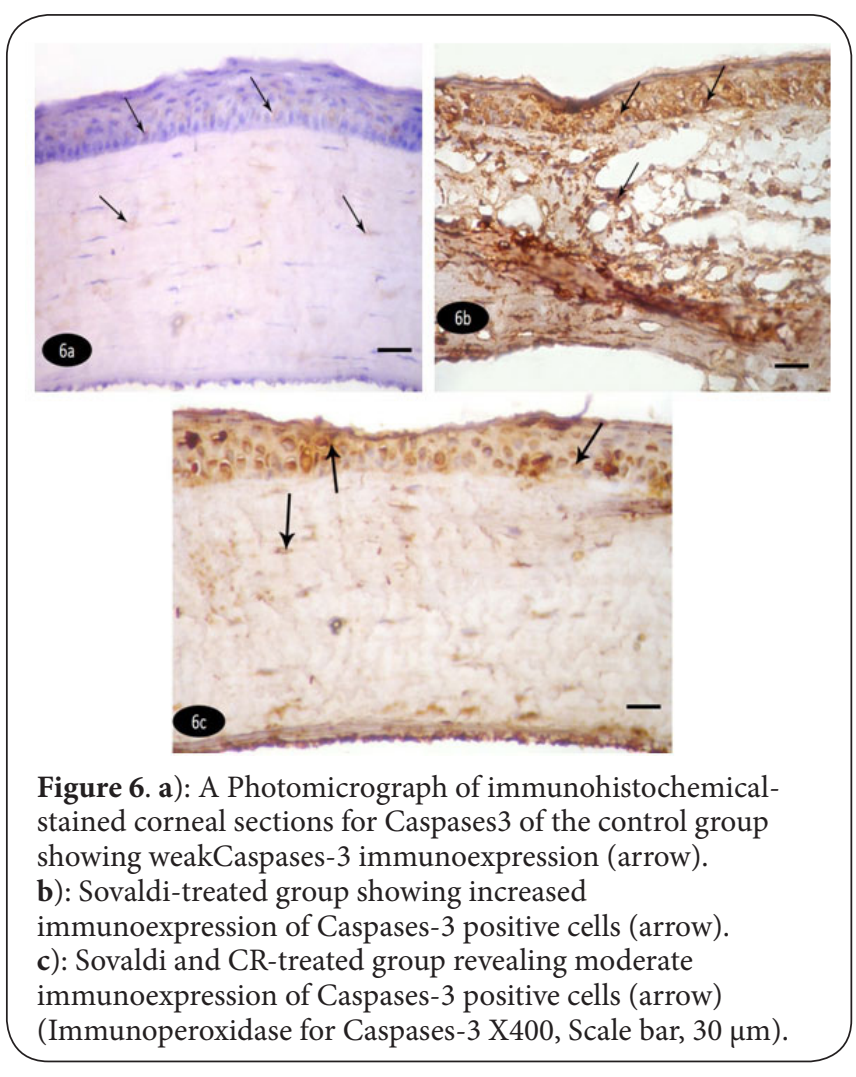

Morphomerical and statistical results

Table 1-3.

\section{Discussion}

Sofosbuvir induced blurred vision necessitated the aim of this study which was the demonstration of the histological adverse effects of the Sofosbuvir administration on cornea. In this study, examination of H\&E stained sections of the cornea revealed disturbance of its normal architecture in the form of irregular upper free surface together with exfoliation and desquamation of some surface epithelial cells. Some sections showed thinning of the epithelium.

In this study, there were irregular upper free surface together with exfoliation and desquamation of some surface epithelial cells, these changes were statistically proved by down-regulation of E-cadherin expression in epithelial cells this was in agreement with [15] The previous changes were attributed to breakdown of tight junctional integrity in the epithelial cells allowing direct passage of hydrophilic molecule through paracellular space to the cornea [16], which explained by marked reduction of a tight junction-related protein (zonula occludin-1) that markedly reduced in epithelial cells followed by disruption of epithelial barrier functions [17]. It was reported that the corneal epithelium is a good sensor which may reflect functional alterations of the cell membrane integrity and was considered as a manifestation of drug toxicity [18]. 
Mekawy et al., Journal of Histology \& Histopathology 2019,

http://www.hoajonline.com/journals/pdf/2055-091X-6-5.pdf

Table 1. Comparison between mean values of the mean area percentage of collagen fibers in all studied group using ANOVA test.

\begin{tabular}{llllll}
\hline & Control I & Group II & Group III & F & P \\
\hline $\begin{array}{l}\text { Area \% } \\
\text { of Mallory trichrome }\end{array}$ & $20.23 \pm 1.21$ & $6.38 \pm 0.68$ & $17.03 \pm 1.26$ & $\mathbf{4 2 4 . 3}$ & $<\mathbf{0 . 0 0 1}^{* *}$ \\
\hline$* *$ highly significant $(\mathrm{p}<0.001)$. & & & & & \\
\hline
\end{tabular}

Table 2. Comparison between mean values of optical density E-cadherin immuno reactions in all studied groups using ANOVA test.

\begin{tabular}{llllll}
\hline & Control I & Group II & Group III & F & P \\
\hline Optical density E-Cadherin & $62.26 \pm 0.80$ & $25.18 \pm 5.27$ & $40.66 \pm 4.33$ & $\mathbf{8 7 0 . 6}$ & $<\mathbf{0 . 0 0 1}^{\star *}$ \\
\hline$* *$ : highly significant $(\mathrm{p}<0.001)$. & & & & &
\end{tabular}

Table 3. Comparison between mean values of the optical density of Caspases-3 immunoreaction in all studied groups using ANOVA test.

\begin{tabular}{llllll}
\hline & Control I & Group II & Group III & F & P \\
\hline Optical density of caspases-3 & $51 \pm 0.20$ & $60.8 \pm 2.17$ & $55.66 \pm 0.33$ & $\mathbf{3 9 . 0 . 6}$ & $<\mathbf{0 . 0 0 1}^{\star *}$ \\
\hline${ }^{* *}$ : highly significant $(\mathrm{p}<0.001)$. & & & &
\end{tabular}

E-cadherin is an essential adhesion molecule that maintains the corneal epithelial structural and functional integrity; the reduction of E-cadherin expression mostly indicated the altered integrity of the epithelial cell layers with impaired packing and organization of the cells [19]. This is in agreement with our result including reduction of E-cadherin expression together with sloughing of the epithelium in Sofosbuvir treated group. Disturbance of epithelial integrity could lead to impairment of its barrier function, this exposes the corneal stroma and leads to disruption of its collagen bundles causing severe defect of vision due to loss of its transparency and so light refraction [20].

Bowman's layer was interrupted and separated from the epithelial layer. It was suggested by Saika et al [21] who mentioned that damaged corneal epithelial cells produce substances like metalloproteinases which are capable of degrading components of the basement membrane (BM) resulting in alterations of its structure and function.

Decreased keratocyte of the stroma detected in this study might be due to their contraction, apoptosis \& death as previously shown by Rosin and Bell [22]. Disarrangement, destruction and loss of collagen fibers might be explained by apoptosis \& loss of keratocytes as keratocytes synthesize and maintain stromal collagen, so loss of keratocytes would result in decreased collagen production. It could also stimulate the production of matrix metalloproteinase enzymes (MMPs) in corneal stromal cell which are collagen degradation enzymes leading to increase collagen turn over with a net loss of stromal collagen as previously reported by Manni et al [23].

Concerning caspase-3 expression in Sovaldi- treated groups of the current study; there was highly significant increase in the expression of caspase-3, a marker for apoptosis, which appear in the epithelial cells, stromal and endothelial cells. Kim et al., 2011 [24] attributed the apoptosis in cases of Diabetic
Keratopathy (DK) to the accumulation of NF-KB (necrosis factor kappa beta) in the corneal tissues of diabetic rats. In addition, Circu and Aw, 2010 [25] postulated that the excessive production of ROS played an important role in apoptosis.

Wide separation of stromal collagen fibers which were also proved by Mallory trichrome stain [26] explained this separation by reaction of cautions with the carboxyl groups of stromal collagen and glycoaminoglycans causing disarrangement to the collagen bundles. The keratocytes implicated in maintaining the highly organized collagen fibrils and the intercellular matrix, more keratocytes means better function [27].

Considerable attention is currently focused on the consumption of functional foods for the protection of human health. In particular, there is intense interest in the role of dietary antioxidants, which are capable of scavenging the oxidants and free radicals responsible for initiating various diseases [28]. Systematic investigations of the antioxidant Systematic investigations of the antioxidant properties of various foods, beverages, spices, and herbs have been performed [29]. Recently, a number of studies have shown that chrysin has multiple biological activities, such as anti-inflammatory, anti-oxidant, and anticancer effects [30].

In chrysin treated group, there were less degenerative changes in cornea: more or less normal appearance of corneal epithelium, stroma and Descemet's membrane with mild separation of Bowman's membrane from epithelium and slight stromal separation. There werereduction of caspases3positive cells in comparison with the Sofaldi treated group, which were statistically proved. Chrysin has been shown to inhibit tumor angiogenesis in vivo, which is a key step in metastasis [31]. Chrysin may inhibit chymotrypsin-like and trypsin-like proteasomes, which play an important role in regulating apoptosis and the cell cycle [32].

There were improvement of collagen synthesis after treat- 
ment by chrysin, this was attributed to the collagen stimulating activity observed for some flavonoids, by inhibiting matrix metalloproteinases (MMP), flavonoids could increase the rate and the amount of collagen synthesized by fibroblasts necessary for the formation of new wound matrix, thereby speeding up the healing process [33].

\section{Conclusion and recommendations}

Sofosbuvir cause several deleterious effects to cornea. These effects s might lead to blurring of vision and decrease visual acuity. Yet, the scientific community should dedicate attention to establish and validate well designed protocols for treatment of hepatitis $C$ viral infection and increase the uptake of natural flavonoids as chrysin.

\section{Competing interests}

The authors declare that they have no competing interests.

\section{Authors' contributions}

\begin{tabular}{|l|c|c|c|}
\hline Authors' contributions & NHM & HMA & NEI \\
\hline Research concept and design & $\checkmark$ & $\checkmark$ & $\checkmark$ \\
\hline Collection and/or assembly of data & $\checkmark$ & $\checkmark$ & $\checkmark$ \\
\hline Data analysis and interpretation & $\checkmark$ & $\checkmark$ & $\checkmark$ \\
\hline Writing the article & $\checkmark$ & $\checkmark$ & $\checkmark$ \\
\hline Critical revision of the article & $\checkmark$ & $\checkmark$ & $\checkmark$ \\
\hline Final approval of article & $\checkmark$ & $\checkmark$ & $\checkmark$ \\
\hline Statistical analysis & $\checkmark$ & $\checkmark$ & $\checkmark$ \\
\hline
\end{tabular}

Publication history

Editor: Giuseppe Musumeci, University of Catania, Italy. Received: 31-July-2019 Final Revised: 05-Sept-2019

Accepted: 10-Sept-2019 Published: 15-Oct-2019

\section{References}

1. Berden FA, Kievit W, Baak LC, Bakker CM, Beuers U, Boucher CA, Brouwer JT, Burger DM, van Erpecum KJ, van Hoek B, Hoepelman Al, Honkoop P, Kerbert-Dreteler MJ, de Knegt RJ, Koek GH, van Nieuwkerk CM, van Soest $\mathrm{H}$, Tan AC, Vrolijk JM and Drenth JP. Dutch guidance for the treatment of chronic hepatitis $\mathrm{C}$ virus infection in a new therapeutic era. Neth J Med. 2014; 72:388-400.| | Pdf | PubMed

2. Lawitz E, Mangia A, Wyles D, Rodriguez-Torres M, Hassanein T, Gordon SC, Schultz M, Davis MN, Kayali Z, Reddy KR, Jacobson IM, Kowdley KV, Nyberg L, Subramanian GM, Hyland RH, Arterburn S, Jiang D, McNally J, Brainard D, Symonds WT, McHutchison JG, Sheikh AM, Younossi Z and Gane EJ. Sofosbuvir for previously untreated chronic hepatitis $C$ infection. N Engl J Med. 2013; 368:1878-87. | Article | PubMed

3. Fung $A$, Jin Z, Dyatkina $N$, Wang $G$, Beigelman $L$ and Deval J. Efficiency of incorporation and chain termination determines the inhibition potency of 2'-modified nucleotide analogs against hepatitis $\mathrm{C}$ virus polymerase. Antimicrob Agents Chemother. 2014; 58:3636-45. | Article | PubMed Abstract I PubMed FullText

4. Karageorgopoulos D.E, El-Sherif O, Bhagani S and Khoo S.H. Drug interactions between antiretrovirals and new or emerging direct-acting antivirals in HIV/hepatitis C virus confection. Curr Opin Infect Dis. 2014; 27:36-45.

5. FDA. U.S. Food and Drug Administration. FDA Drug Safety Communication. 2015.

6. Andrasko $G$ and Ryen K. Corneal staining and comfort observed with traditional and silicone hydrogel lenses and multipurpose solution combinations. Optometry. 2008; 79:444-54. | Article | PubMed
7. Abdul Hamid Z, Budin SB, Wen Jie N, Hamid A, Husain K and Mohamed J. Nephroprotective effects of Zingiber zerumbet Smith ethyl acetate extract against paracetamol-induced nephrotoxicity and oxidative stress in rats. J Zhejiang Univ Sci B. 2012; 13:176-85. | Article | PubMed Abstract | PubMed FullText

8. Topal F, Nar M, Gocer H, Kalin P, Kocyigit UM, Gulcin I and Alwasel SH. Antioxidant activity of taxifolin: an activity-structure relationship. J Enzyme Inhib Med Chem. 2016; 31:674-83. | Article I PubMed

9. Mehri S, Karami HV, Hassani FV and Hosseinzadeh H. Chrysin reduced acrylamide-induced neurotoxicity in both in vitro and in vivo assessments. Iran Biomed J. 2014; 18:101-6. | Article | PubMed Abstract I PubMed FullText

10. Mantawy EM, El-Bakly WM, Esmat A, Badr AM and El-Demerdash E. Chrysin alleviates acute doxorubicin cardiotoxicity in rats via suppression of oxidative stress, inflammation and apoptosis. Eur J Pharmacol. 2014; 728:107-18. | Article | PubMed

11. Ali N, Rashid S, Nafees S, Hasan SK and Sultana S. Beneficial effects of Chrysin against Methotrexate-induced hepatotoxicity via attenuation of oxidative stress and apoptosis. Mol Cell Biochem. 2014; 385:215-23. I Article | PubMed

12. Pushpavalli G, Kalaiarasi P, Veeramani $C$ and Pugalendi KV. Effect of chrysin on hepatoprotective and antioxidant status in D-galactosamineinduced hepatitis in rats. Eur J Pharmacol. 2010; 631:36-41. | Article | PubMed

13. Bancroft J.D and Gamble M. Theory and practice of histological techniques. 8th ed. 2013; 601-15.

14. Ramos-Vara JA, Kiupel M, Baszler T, Bliven L, Brodersen B, Chelack B, Czub S, Del Piero F, Dial S, Ehrhart EJ, Graham T, Manning L, Paulsen D, Valli VE and West K. Suggested guidelines for immunohistochemical techniques in veterinary diagnostic laboratories. J Vet Diagn Invest. 2008; 20:393-413. | Article | PubMed

15. Issa N.M and El-Sherif N.M. Histological and Immunohistochemical Studies on the Cornea and Retina of Sofosbuvir Treated Rats. Austin J Anat. 2017; 4:1068.

16. Amany M. Histological and Immunohistochemical Study on the Effect of Polyhexanide-Preserved Contact Lens Solution on Albino Rat Cornea and the Possible Protective Role of Carboxymethyl cellulose. Egypt J Histol. 2010; 33:288-300.

17. Geerling G, Daniels JT, Dart JK, Cree IA and Khaw PT. Toxicity of natural tear substitutes in a fully defined culture model of human corneal epithelial cells. Invest Ophthalmol Vis Sci. 2001; 42:948-56. | Article | PubMed

18. Maurer JK, Molai A, Parker RD, Li LI, Carr GJ, Petroll WM, Cavanagh HD and Jester JV. Pathology of ocular irritation with acetone, cyclohexanol, parafluoroaniline, and formaldehyde in the rabbit low-volume eye test. Toxicol Pathol. 2001; 29:187-99.| | Article | PubMed

19. Dwivedi DJ, Pontoriero GF, Ashery-Padan R, Sullivan S, Williams T and West-Mays JA. Targeted deletion of AP-2alpha leads to disruption in corneal epithelial cell integrity and defects in the corneal stroma. Invest Ophthalmol Vis Sci. 2005; 46:3623-30. | Article | PubMed Abstract | PubMed FullText

20. Murata T, Ishibashi T and Inomata $\mathrm{H}$. Immunohistochemical detection of extravasated fibrinogen (fibrin) in human diabetic retina. Graefes Arch Clin Exp Ophthalmol. 1992; 230:428-31. | Article | PubMed

21. Wei Ming Z, Qichuan Z and Ming Z. Neurogenesis in Adult Human BrainAfter Traumatic Brain Injury. J Neurotrauma. 2013; 30:1872-80.

22. Rosin LM and Bell NP. Preservative toxicity in glaucoma medication: clinical evaluation of benzalkonium chloride-free $0.5 \%$ timolol eye drops. Clin Ophthalmol. 2013; 7:2131-5. | Article | PubMed Abstract | PubMed FullText

23. Manni G, Centofanti M, Oddone F, Parravano M and Bucci A.M. Interleukin-1 Tear Concentration in Glaucomatous and Ocular Hypertensive Patients Treated with Preservative-Free Non selective Beta-Blockers. Am J Ophthalmol. 2005; 139:72- 77.

24. Kim J, Kim CS, Sohn E, Jeong IH, Kim H and Kim JS. Involvement of advanced glycation end products, oxidative stress and nuclear factor- 
Mekawy et al., Journal of Histology \& Histopathology 2019,

http://www.hoajonline.com/journals/pdf/2055-091X-6-5.pdf

kappaB in the development of diabetic keratopathy. Graefes Arch Clin Exp Ophthalmol. 2011; 249:529-36. | Article | PubMed

25. Circu ML and Aw TY. Reactive oxygen species, cellular redox systems, and apoptosis. Free Radic Biol Med. 2010; 48:749-62. | Article | PubMed Abstract | PubMed FullText

26. Bantseev V, McCanna DJ, Driot JY and Sivak JG. The effects of toxicological agents on the optics and mitochondria of the lens and the mitochondria of the corneal epithelium. Semin Cell Dev Biol. 2008; 19:150-9. | Article | PubMed

27. Xu L, Overbeek PA and Reneker LW. Systematic analysis of E-, N- and P-cadherin expression in mouse eye development. Exp Eye Res. 2002; 74:753-60. | Article | PubMed

28. Rice-Evans C.A, Miller N.J and Paganga G. Structure-antioxidant activityrelationships of flavonoids and phenolic acids. Free Radical Biology \&Medicine. 1996; 20:933-56.

29. Stasko A, Polovka M, Brezova V, Biskupic S, Malık F and Tokay. Wines as scavengers of free radicals (an EPR study). Food Chemistry. 2006; 96:185-96.

30. Cho H, Yun CW, Park WK, Kong JY, Kim KS, Park Y, Lee S and Kim BK. Modulation of the activity of pro-inflammatory enzymes, COX-2 and iNOS, by chrysin derivatives. Pharmacol Res. 2004; 49:37-43. | Article | PubMed

31. Fu B, Xue J, Li Z, Shi X, Jiang BH and Fang J. Chrysin inhibits expression of hypoxia-inducible factor-1alpha through reducing hypoxia-inducible factor-1alpha stability and inhibiting its protein synthesis. Mol Cancer Ther. 2007; 6:220-6. | Article | PubMed

32. Wu YX and Fang $X$. Apigenin, chrysin, and luteolin selectively inhibit chymotrypsin-like and trypsin-like proteasome catalytic activities in tumor cells. Planta Med. 2010; 76:128-32. | Article | PubMed

33. Sin B.Y and Kim, H.O. Inhibition of collagenase by naturallyoccuring flavonoids. Arch Pharm Res. 2005; 28:1152-1155.

\section{Citation:}

Mekawy NH, Abdel-aziz HM and Ibrahem NE.

Protective Effect of Chrysin on Corneal Structural Alterations Induced by Sofosbuvir in Male Albino Rats (Histological and Immunohistochemical Study). J Histol Histopathol. 2019; 6:5.

http://dx.doi.org/10.7243/2055-091X-6-5 